\title{
Detection of Clinical Mastitis with the Help of a Thermal Camera
}

\author{
M. Hovinen, ${ }^{*} \dagger^{1}$ J. Siivonen, ${ }^{\star} \dagger \ddagger$ S. Taponen, ${ }^{*}$ L. Hänninen, ${ }^{\star} \dagger$ M. Pastell, $† \S$ A.-M. Aisla, $\S$ and S. Pyörälä ${ }^{\star}$ \\ ${ }^{*}$ Department of Production Animal Medicine, PO Box 57, FI-00014 University of Helsinki, Finland \\ †Research Centre for Animal Welfare, PO Box 57, FI-00014 University of Helsinki, Finland \\ $\ddagger$ MTT Agrifood Research, Animal Production Research, FI-31600 Jokioinen, Finland \\ $\S$ Department of Agrotechnology, PO Box 28, FI-00014 University of Helsinki, Finland
}

\section{ABSTRACT}

Increasing dairy farm size and increase in automation in livestock production require that new methods are used to monitor animal health. In this study, a thermal camera was tested for its capacity to detect clinical mastitis. Mastitis was experimentally induced in 6 cows with $10 \mu \mathrm{g}$ of Escherichia coli lipopolysaccharide (LPS). The LPS was infused into the left forequarter of each cow, and the right forequarters served as controls. Clinical examination for systemic and local signs and sampling for indicators of inflammation in milk were carried out before morning and evening milking throughout the 5-d experimental period and more frequently on the challenge day. Thermal images of experimental and control quarters were taken at each sampling time from lateral and medial angles. The first signs of clinical mastitis were noted in all cows $2 \mathrm{~h}$ postchallenge and included changes in general appearance of the cows and local clinical signs in the affected udder quarter. Rectal temperature, milk somatic cell count, and electrical conductivity were increased $4 \mathrm{~h}$ postchallenge and milk $\mathrm{N}$-acetyl- $\beta$-D-glucosaminidase activity 8 $\mathrm{h}$ postchallenge. The thermal camera was successful in detecting the 1 to $1.5^{\circ} \mathrm{C}$ temperature change on udder skin associated with clinical mastitis in all cows because temperature of the udder skin of the experimental and control quarters increased in line with the rectal temperature. Yet, local signs on the udder were seen before the rise in udder skin and body temperature. The udder represents a sensitive site for detection of any febrile disease using a noninvasive method. A thermal camera mounted in a milking or feeding parlor could detect temperature changes associated with clinical mastitis or other diseases in a dairy herd.

Key words: infrared thermography, mastitis detection, thermal camera

Received April 1, 2008.

Accepted August 6, 2008.

${ }^{1}$ Corresponding author: mari.hovinen@helsinki.fi

\section{INTRODUCTION}

Increasing herd size and the rapid increase in labor costs in Europe have required greater automation in livestock production. Mastitis is the most common disease in dairy cows and causes the heaviest economic losses to the dairy industry. Automated methods for early and reliable detection of mastitis are urgently needed. Several techniques exist to analyze automatically deviations in milk, including analysis of electrical conductivity (EC), color of milk, and SCC. Yet, these techniques are either not sufficiently precise (EC, color) for detection of early signs of the disease and for automatic diversion of infected milk (Rasmussen, 2004; Hovinen et al., 2006), or they have not been scientifically validated for detection of clinical mastitis in automatic milking systems (SCC). New sensor technologies such as measuring the volatile components and potentiometric values of milk are being researched (Eriksson et al., 2005; Mottram et al., 2007). A newly invented biosensor system that analyses lactose and EC has been claimed to have a sensitivity of $>90 \%$ for identifying quarters with $\geq 100,000$ cells $/ \mathrm{mL}$, irrespective of the type of mastitis (Culina et al., 2006). Moreover, the method is still under development. There is a need for a detection method that is not related to milking, for detecting mastitis during the dry period, before first calving, and for cases of severe clinical mastitis, when clinical signs appear before changes in milk.

Infrared thermography (IRT) is a noninvasive method for measuring radiated heat emitted by the skin, reflecting subcutaneous circulation and metabolism (Jones and Plassmann, 2002). Clinical mastitis leads to systemic (fever, inappetence) and local signs in the udder quarter (swelling, pain, and heat; Radostits et al., 2007). Radiated heat emitted by the udder can be detected with IRT, but IRT was not suitable for early detection of subclinical mastitis (Barth, 2000). Berry et al. (2003) developed a predictive model for the temperature of the udder surface based on consecutive measurements of healthy cows and ambient temperature. They concluded that IRT showed promise for early detection of mastitis. A thermal camera was tested for detection 
of respiratory disease in calves (Schaefer et al., 2007), back pain in horses (Fonseca et al., 2006), hoof disorders of cows (Nikkhah et al., 2005), viral diarrhea of calves (Schaefer et al., 2004), and the effect of milking on teat tissue (Paulrud et al., 2005).

The aim was to test the noninvasive, non-milkingrelated IRT method for early detection of acute clinical mastitis in dairy cows. Mastitis was experimentally induced using Escherichia coli endotoxin, and development of mastitis was monitored with several indicators of inflammation measured from milk and with IRT images.

\section{MATERIALS AND METHODS}

\section{Animals and Experimental Protocol}

Six cows were used as experimental animals (5 Finnish Ayrshire and 1 Holstein-Friesian); 5 cows were in first lactation and 1 cow in second lactation. Udder hair was carefully clipped before the experiment. Cows were housed in a stanchion barn of 68 milking cows in stalls bedded with wood shavings. The cows had free access to good quality silage and water and were fed with concentrate 6 times daily according to their state of lactation. The cows were milked twice daily, with a pipeline milking machine (DeLaval Harmony, DeLaval International AB, Tumba, Sweden) at 0530 and 1730 h. Milk yield of the cows was $26.7 \mathrm{~kg} / \mathrm{d}(\mathrm{SD} \pm 6.9 \mathrm{~kg})$. The cows were in late lactation (190 \pm 34 DIM; range from 155 to 249 DIM).

The cows were clinically healthy. Mean milk SCC of 3 samples taken 194, 26, and $14 \mathrm{~h}$ before the challenge in all quarters was $<250,000$ cells $/ \mathrm{mL}$, and SCC of all samples of experimental quarters was $<100,000$ cells/ $\mathrm{mL}$. All quarters were free of mastitis pathogens. Milk samples were taken during the experiment to detect possible infections which could interfere with the results.
The experimental period was $5 \mathrm{~d}$, referred to as d $-1,0$, and 1 to 3 . Day -1 served as a control day for the thermal camera assessment. The left front udder quarter of each of the cows was infused with $5 \mathrm{~mL}$ of pyrogen-free $\mathrm{NaCl}$ on $\mathrm{d}-1$, at $0700 \mathrm{~h}$. On d 0 , the same quarter was challenged with $10 \mu \mathrm{g}$ of $E$. coli O55:B5 LPS (Sigma-Aldrich Inc., St. Louis, MO) diluted in 5 $\mathrm{mL}$ of $\mathrm{NaCl}$. The right front quarter served as an intact control. The experimental protocol is shown in Table 1.

The experiment was performed according to the approved experimental protocol, under the permission given by the Ethics Committee for animal experiments of the University of Helsinki, Finland.

\section{Clinical Examination, Thermal Imaging, and Milk Sampling}

Clinical examination of the cows included recording the rectal temperature $\left(\mathbf{T}_{\mathbf{R}}\right)$, determination of the systemic signs of the cow, determination of the local signs of the udder, and estimation of the milk appearance. Clinical signs of the cow were assigned to 3 categories: normal, mild to moderate, or severe (modified from the system of the International Dairy Federation, 1999). Systemic status was defined as normal, if the cow was attentive and had good appetite; mild to moderate, if the appetite was decreased and the cow was depressed; and severe, if the cow was apathetic and anorectic. Local signs were defined as normal, if the udder was not swollen; mild to moderate, if the udder was slightly swollen; and severe, if the udder was painful and very swollen. Milk appearance was defined as normal, if the milk was white and homogeneous; as mildly to moderately changed, if the milk was slightly discolored or contained small flakes; and as severely changed, if the milk was strongly discolored, watery, or contained large clots.

Table 1. Protocol for experimental mastitis in 6 cows induced with Escherichia coli LPS

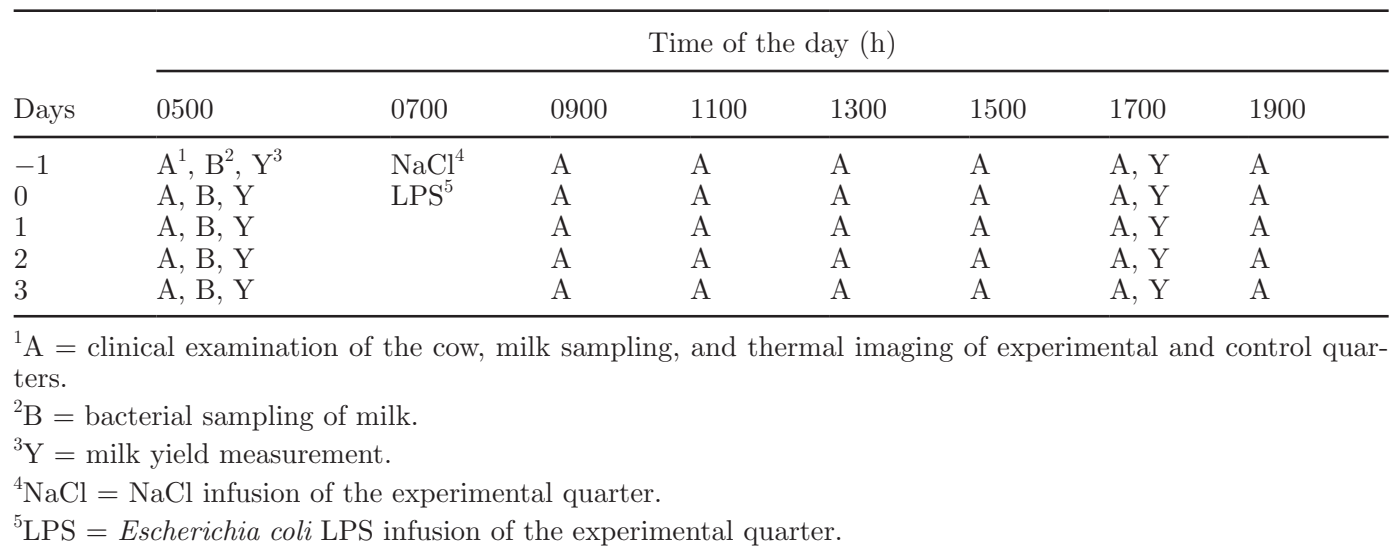




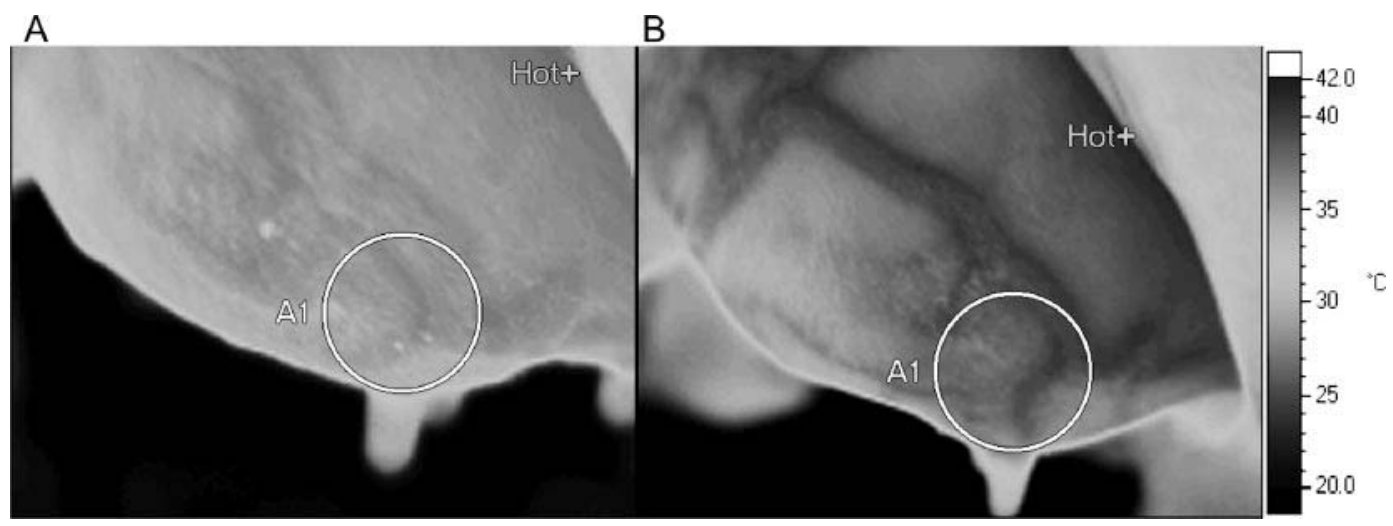

Figure 1. Thermal images of the lateral angle of the experimental udder quarter (left fore) a) before and b) during the infection. A1 = 40 $\times 40$ pixel area above the teat; Hot $+=$ position of the maximum udder skin temperature of the image.

Thermal images were taken to monitor changes in the udder skin temperature $\left(\mathbf{T}_{\mathbf{U}}\right)$ of the experimental and control quarters. Images were taken at every sampling throughout the experimental period with a handheld thermal camera (IR FlexCam Pro, Infrared solutions, Fluke Company, Everett, WA). Images were taken before the clinical examination and milk sampling of the udder, approximately $50 \mathrm{~cm}$ from the udder. The orientation of the images was from the lateral and medial angles of the quarters. The maximum temperature of every image was used in the analysis because it was automatically available, and it had the highest correlation with $T_{R}$. Nevertheless, the maximum temperature of the image was not always on the area of the target quarter, and therefore, the mean temperature of a circle of $40 \times 40$ pixels above the teat was measured. The circle was drawn by hand with the help of the camera software, starting just above the teat and centered according to the teat (Figure 1). This area expressed the smallest normal variation in temperature of the udder (Barth, 2000). An example of the thermal images before and during the inflammation is shown in Figure 1.

Milk samples $(25 \mathrm{~mL})$ were obtained for cow-side EC measurement and evaluation of the milk appearance after the first milk was discarded. Samples $(2 \mathrm{~mL})$ were stored at $-20^{\circ} \mathrm{C}$ for milk $\mathrm{N}$-acetyl- $\beta$-D-glucosaminidase (NAGase) activity analysis. The remaining samples were sent to the laboratory of the Department of Production Animal Medicine for SCC analysis. The samples for bacterial analysis were taken aseptically, cooled immediately in the refrigerator, and sent to the same laboratory.

\section{Thermal Camera}

The thermal camera used operated in the 8- to $14-\mu \mathrm{m}$ spectral band. The thermal resolution of the camera was $0.09^{\circ} \mathrm{C}$, and it was calibrated from 0 to $100^{\circ} \mathrm{C}$. The camera used micro bolometer detectors and had a 160 $\times 120$ focal plane array. The camera had an internal recalibration feature, which automatically calibrated the detector to give correct readings for the ambient temperature. The emissivity value was set to 0.98 , which was the value used for measuring the temperature of human skin (Jones and Plassmann, 2002).

\section{Analytical Methods}

Bacterial samples were analyzed using conventional methods (Hogan et al., 1999). Electrical conductivity was measured with a handheld meter (Lutron CD-4301, Lutron Electronic Enterprise Co., Taipei, Taiwan). Somatic cell count was determined with an electronic counter DCC (DeLaval International AB). Milk NAGase activity was measured with a fluorometric method, modified from that of Mattila (1985). The calibrated milk sample was replaced with a control milk sample with known 4-MU concentration, and NAGase activity was expressed as picomoles of $4-\mathrm{MU} / \mathrm{min} / \mu \mathrm{L}$ of milk at room temperature, instead of in arbitrary units. The upper detection limit for NAGase activity was $24.5 \mathrm{pmol}$ of $4-\mathrm{MU} / \mathrm{min} / \mu \mathrm{L}$ of milk. The interassay and intraassay CV for the NAGase activity analyses were 3.7 and $7 \%$.

\section{Statistical Analysis}

The effect of mastitis on inflammation indicators in milk and $\mathrm{T}_{\mathrm{U}}$ were analyzed with a mixed model, taking repeated measures into account. The fixed factors were the hour (the time from the induction of mastitis), quarter (experimental or control), and the interaction between the hour and quarter. The cow was deemed a random effect. No covariates were used. The $T_{R}$ 


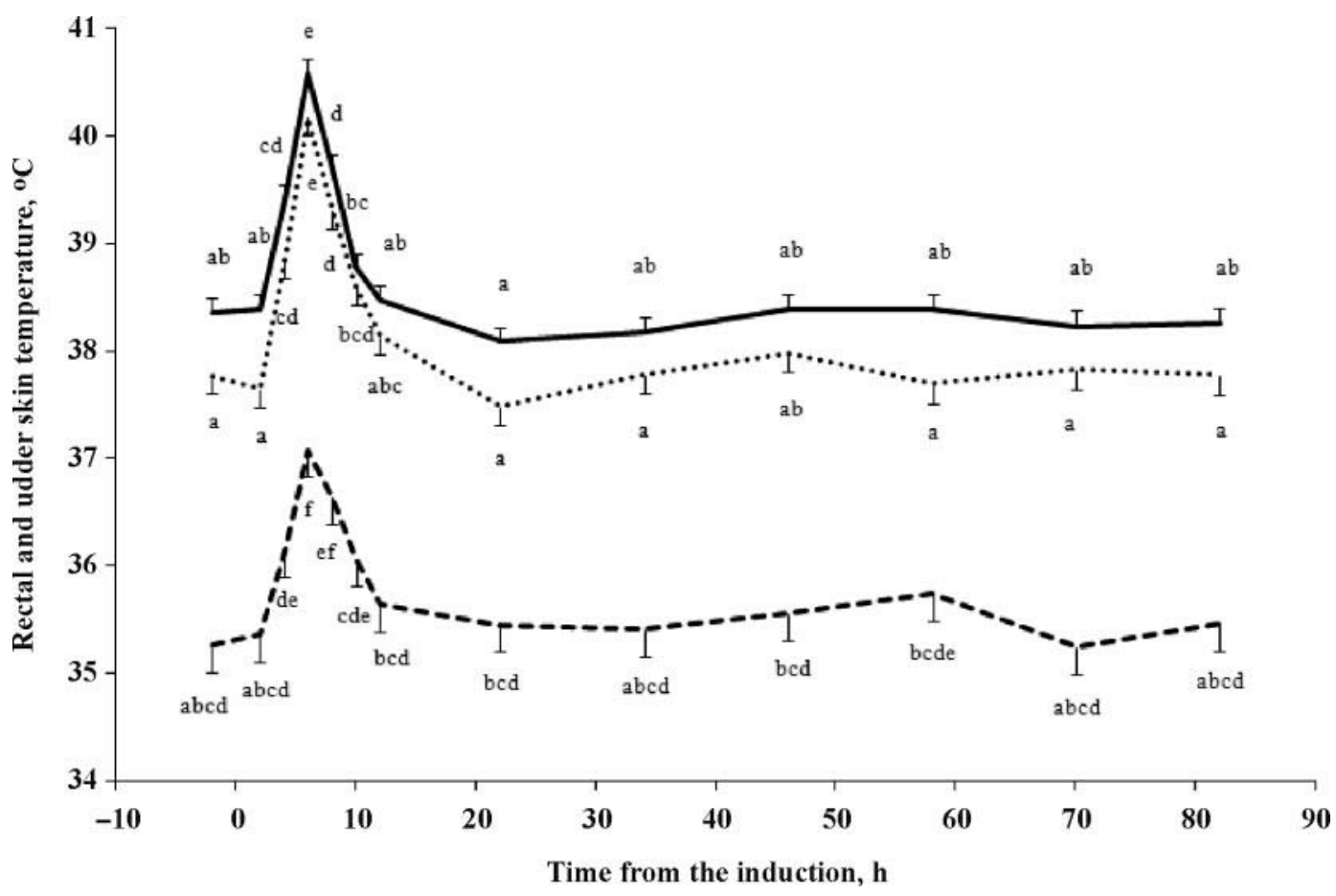

Figure 2. Rectal temperature (solid line), maximum udder skin temperature of the image (dotted line) and udder skin temperature of the $40 \times 40$ pixel area above the teat (dashed line) of the lateral angle of the experimental quarters of 6 cows throughout the experimental period, excluding the d $-1, \pm$ SE. Escherichia coli LPS was infused at time point $0 .{ }^{\text {a }}{ }^{-f}$ Different letters indicate statistically significant differences between mean temperatures $(P<0.05)$ of different sampling times.

was analyzed with a model equivalent to the model described above, except that only the hour was a fixed effect. Normality of distribution was analyzed from the residuals. Homogeneity of variances was evaluated with a scatter plot of residuals and predicted values. Pearson's correlation coefficient was calculated between $T_{R}$ and $\mathrm{T}_{\mathrm{U}}$. All statistical analyses were conducted with the SPSS 13.0 for Windows (SPSS Inc., Chicago, IL).

\section{RESULTS}

\section{Clinical Signs}

All cows developed clinical mastitis after the LPS challenge. Mean $\mathrm{T}_{\mathrm{R}}$ was increased from 4 to $8 \mathrm{~h}$ postchallenge (PC; $P<0.001$; Figure 2 ). The $\mathrm{T}_{\mathrm{R}}$ of all cows increased up to or $>39.2^{\circ} \mathrm{C}$ from 4 (4 cows) or 6 (2 cows) $\mathrm{h}$ PC and remained $>39.2^{\circ} \mathrm{C}$ until 8 (1 cow) to 12 (5 cows) h PC. Body temperature peaked in all cows at $6 \mathrm{~h} \mathrm{PC}$.

All cows had mild to moderate systemic and local signs and changes in the milk appearance $2 \mathrm{~h}$ PC with few exceptions; changes in the milk appearance of 1 cow were seen $4 \mathrm{~h} \mathrm{PC}$, and local signs and changes in the milk appearance of another cow were seen $4 \mathrm{~h}$ PC. The systemic signs continued until 8 or $10 \mathrm{~h} \mathrm{PC}$.
All quarters except 1 were swollen until the end of the experimental period. Milk appearance did not normalize during the entire experimental period. Local signs in the udder were severe in 5 cows on the day of the challenge. Severe changes in milk appearance were visible with 3 cows in sporadic samplings. Local signs or changes in the milk appearance were not detected in the control quarters. The milk yield of the cows of $\mathrm{d}$ -1 and morning milking of $\mathrm{d} 0$ was $13.0 \pm 0.4 \mathrm{~kg}$ per milking and at the evening milking of $\mathrm{d} 0$ and at both milkings of $\mathrm{d} 1$ was $11.5 \pm 0.1 \mathrm{~kg}$ per milking $(P=$ $0.50)$.

\section{Thermal Images}

Mean $\mathrm{T}_{\mathrm{U}}$ of the experimental and control quarters were increased $4 \mathrm{~h} \mathrm{PC}$ (Figure $2 ; P<0.01$ ). The $\mathrm{T}_{\mathrm{U}}$ of a cow did not increase before $T_{R}$ was increased, and the correlation between $T_{R}$ and mean $T_{U}$ of the lateral angle of the drawn circle was $\mathrm{r}=0.92(P<0.001)$, and the correlation between $\mathrm{T}_{\mathrm{R}}$ and maximum $\mathrm{T}_{\mathrm{U}}$ of the lateral angle of the image was $\mathrm{r}=0.98(P<0.001)$. The maximum $\mathrm{T}_{\mathrm{U}}$ of the image and the mean $\mathrm{T}_{\mathrm{U}}$ of the drawn circle increased in parallel for both angles of the experimental and control quarters. At 6 h PC, 5 of the 6 cows had clearly increased mean $\mathrm{T}_{\mathrm{U}}$ of the drawn circle 


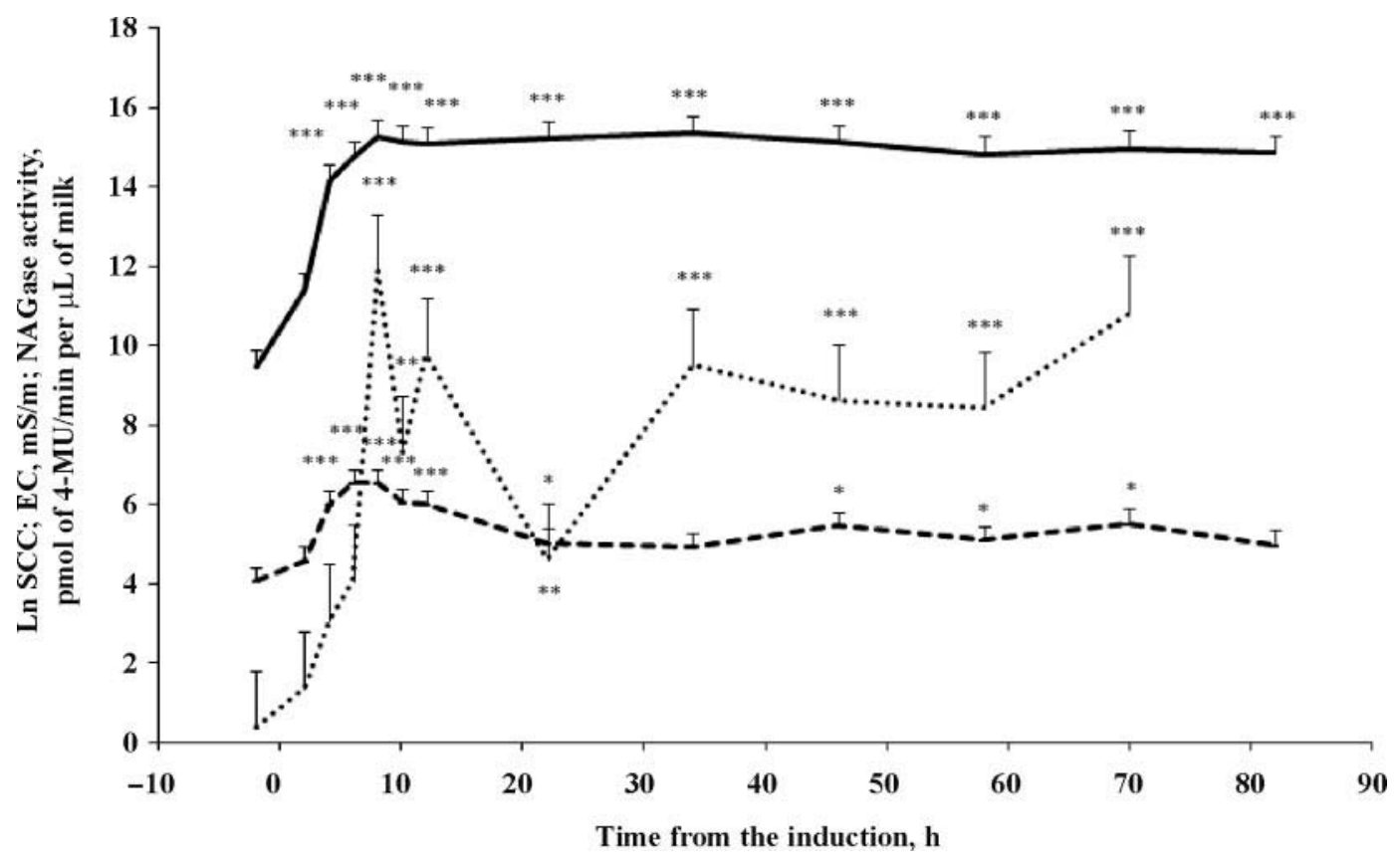

Figure 3. Mean milk ln SCC (solid line), mean N-acetyl- $\beta$-D-glucosaminidase (NAGase) activity (dotted line), and electrical conductivity (EC; dashed line) of the experimental quarters of 6 cows throughout the experimental period, excluding the $\mathrm{d}-1, \pm$ SE. Escherichia coli LPS was infused at time point 0 . ${ }^{*}$ Indicates that $P<0.05$ compared with the control quarter (data not shown); $* *$ indicates $P<0.01$ and $* * *$ indicates $P<0.001$.

$\left(>1^{\circ} \mathrm{C}\right)$. The increase was not seen in the sixth cow that showed a mild increase in $\mathrm{T}_{\mathrm{R}}$ (maximum $39.2^{\circ} \mathrm{C}$ ). Maximum $\mathrm{T}_{\mathrm{U}}$ of the image was approximately $0.6^{\circ} \mathrm{C}$ higher at the lateral angles than at the medial angles (data not shown). Images taken from the lateral angle of the experimental quarter were warmer than those for the control quarter; in contrast, images from the medial angle of the experimental quarter were colder than those of the control quarter $(P<0.01)$. The $\mathrm{T}_{\mathrm{U}}$ decreased quickly to normal levels, in parallel with or a little later than $\mathrm{T}_{\mathrm{R}}$.

\section{Indicators of Inflammation in Milk}

Figure 3 shows milk SCC, NAGase activity, and EC for the experimental quarters throughout the experimental period, excluding $\mathrm{d}-1$, when the experimental and control quarters did not differ. Milk SCC and EC increased in the experimental quarters from $4 \mathrm{~h} \mathrm{PC}(P$ $<0.001)$ and NAGase activity from $8 \mathrm{~h} \mathrm{PC}(P<0.001)$ compared with the control quarters until the end of the experimental period. The EC of the experimental quarters did not differ from that of the control quarters at 34 and $82 \mathrm{~h} \mathrm{PC}$. Indicators of inflammation in milk of the control quarters stayed normal throughout the experiment (data not shown).

All quarters except 1 were bacterially negative throughout the experiment. Clinical mastitis caused by Klebsiella spp. was detected in the experimental quarter of $1 \mathrm{cow}$ at the evening milking on $\mathrm{d} 2$. This cow was excluded from the analysis for the rest of the samplings.

\section{DISCUSSION}

The clinical course of experimental endotoxin mastitis was similar to that described in earlier studies (Hoeben et al., 2000; Lehtolainen et al., 2003). In studies with a greater LPS dose, local signs and increased $T_{R}$ were detectable $2 \mathrm{~h} \mathrm{PC}$, but changes in the milk appearance were seen later than in our study (Lehtolainen et al., 2003).

The thermal camera showed increased $\mathrm{T}_{\mathrm{U}}$ both in experimental and control quarters $4 \mathrm{~h} \mathrm{PC}$, in line with the rise in $T_{R}$. This was somewhat unexpected as mild systemic signs, local signs in the udder, and changes in the milk appearance were noted already $2 \mathrm{~h} \mathrm{PC}$. During mastitis, blood vessels of the udder dilate to bring blood cells to the site of infection (Jones and Plassmann, 2002). Hyperemia results in classical signs of infection: calor and rubor (i.e., heat and redness of the udder quarters). Permeability of the capillaries increases and plasma leaks into the interstitium, causing edema, seen as swelling (McGavin and Zachary, 2007), which, in turn, results in impaired blood circulation and decreased $T_{U}$, which might explain why local signs 
were not detected by IRT. The $\mathrm{T}_{\mathrm{U}}$ normalized parallel to $\mathrm{T}_{\mathrm{R}}$ during the first $24 \mathrm{~h} \mathrm{PC}$, but local signs, milk appearance, and indicators of inflammation in milk reflected an ongoing inflammatory process in the affected quarter until the end of the study period.

Local signs of inflammation were detected with IRT in laminitis of dairy cows and in myositis of the back muscles of horses (Nikkhah et al., 2005; Fonseca et al., 2006). Inflammatory processes without pronounced swelling may result in detectable increases in surface temperature, unlike in our study, where pronounced swelling was present. Scott et al. (2000), by taking thermal images from the caudal aspect of the udder, detected a clear rise in temperature of the experimental quarter and a lower rise in the control quarter $1 \mathrm{~h}$ after induction of mastitis with $10 \mu \mathrm{g}$ of LPS. Rectal temperature did not increase earlier than $6 \mathrm{~h} \mathrm{PC}$ in their study. Explanations for the discrepancy between our results and theirs are difficult to find, due to lack of details provided in their study.

Another possible explanation for unsuccessful detection of local signs in the udder with the IRT lies in the systemic effects of the LPS challenge. The LPS acts as an exogenous pyrogen through cytokine production in the mammary gland, which raises the set point of the body temperature of the hypothalamus. By vasoconstriction of the peripheral blood vessels and shivering, the animal tries to achieve the new set point temperature, leading to fever (McGavin and Zachary, 2007). The IRT showed an equivalent increase of udder temperature in the experimental and control quarters, reflecting a systemic effect of LPS. Local changes in the udder were hidden by the systemic effect, supporting Loughmiller et al. (2001), who suggested that detection with IRT of the early stage of fever in pigs inoculated with Actinobacillus pleuropneumoniae may not have been possible because of vasoconstriction of the blood vessels.

The thermal camera was a viable tool for detecting temperature changes of the udder during clinical mastitis. But, IRT showed no promise in early detection of LPS-induced clinical mastitis because $\mathrm{T}_{\mathrm{U}}$ was closely related to $T_{R}$ but not to the local signs of the udder. With IRT, Hurnik et al. (1984) were able to detect 4 out of 6 naturally occurring cases of mastitis from 1 to 3 $\mathrm{d}$ before the clinical diagnosis. In their study, detection was based on the expansion of the area enclosed by the temperature isotherm of $37^{\circ} \mathrm{C}$ on the gluteal region of the cow, but the recording methods of the clinical mastitis signs were not explained. More studies are needed to establish whether a natural infection with a common course of events, starting with local signs of the udder, would be detected before systemic signs appear.
Schaefer et al. (2004) showed that the position of IRT images is important. Orbital scans were sensitive and an earlier detection of febrile conditions was possible than from scans of the ear, nose, or back. In our study the udder proved to be a suitable site for the measurement. The udder is usually kept short-haired for hygienic reasons. The groove between the udder and the hind leg seemed to show the highest temperatures in the udder area. The $T_{U}$ reflected $T_{R}$ and the maximum temperature of the image was usable, even though not always situated on the actual inflamed quarter.

A thermal camera installed in a milking or feeding parlor might be able to detect acute clinical mastitis with fever before milking, although local signs of the udder indicated mastitis earlier than the thermal images. In future studies, the ability of IRT to automatically detect naturally occurring mastitis and other febrile diseases should be tested in field conditions (e.g., milking parlor or an automatic milking system) before the practical benefits and on-line usage of the system can be considered. In addition, with continuous monitoring of a herd through thermal imaging, possibly in conjunction with behavioral data, this tool might bring additional value to detecting mastitis and other febrile diseases not only in lactating, but also in dry cows. This would be an advantage as compared with monitoring systems associated with milking, but more studies are needed to confirm this.

\section{CONCLUSIONS}

The transient increase of $T_{R}$ of experimentally induced clinical mastitis was successfully detected with the help of a thermal camera. Udder skin temperature rose simultaneously with $T_{R}$. Yet, local inflammatory changes of the udder, appearing earlier than the $T_{R}$ increase, were not detected with IRT. The capacity of IRT to detect naturally occurring clinical mastitis needs to be studied under field conditions, where the systemic inflammatory reaction may be less pronounced. This study showed that the udder is a sensitive site for detection of febrile diseases of dairy cattle by IRT. If mounted in a milking or feeding parlor, the thermal camera, incorporating an appropriate model, could be used to detect mastitis with fever or other febrile diseases.

\section{ACKNOWLEDGMENTS}

We would like to thank Claudio Oliviero (Department of Production Animal Medicine, University of Helsinki) for presenting the original idea for this study, Anu Pirinen (Faculty of Veterinary Medicine, University of Helsinki) for clinical work, the staff of the university 
farm in Viikki, and the laboratory of the Department of Production Animal Medicine. The study was funded by the Veterinary Research Education Program in Veterinary Medicine and Walter Ehrström Foundation.

\section{REFERENCES}

Barth, K. 2000. Basic investigations to evaluate a highly sensitive infrared-thermograph-technique to detect udder inflammation in cows. Milchwissenschaft 55:607-609.

Berry, R. J., A. D. Kennedy, S. L. Scott, B. L. Kyle, and A. L. Schaefer. 2003. Daily variation in the udder surface temperature of dairy cows measured by infrared thermography: Potential for mastitis detection. Can. J. Anim. Sci. 83:687-693.

Culina, M., J. Hahne, and K.-D. Vorlop. 2006. Design of an online sensor array for an early detection of udder affections in automatic milking systems. Pages 453-454 in World Congress of Agricultural Engineering for a Better World: Book of Abstracts. VDI Verlag GmbH, Bonn, Germany.

Eriksson, A., K. Persson Waller, K. Svennersten-Sjaunja, J.-E. Haugen, F. Lundby, and O. Lind. 2005. Detection of mastitic milk using a gas-sensor array system (electronic nose). Int. Dairy J. 15:1193-1201

Fonseca, B. P. A., A. L. G. Alves, J. L. M. Nicoletti, A. Thomassian, C. A. Hussni, and S. Mikail. 2006. Thermography and ultrasonography in back pain diagnosis of equine athletes. J. Equine Vet. Sci. 26:507-516.

Hoeben, D., C. Burvenich, E. Trevis, G. Bertoni, J. Hamann, R. M. Bruckmaier, and J. W. Blum. 2000. Role of endotoxin and TNF-a in the pathogenesis of experimentally induced coliform mastitis in periparturient cows. J. Dairy Res. 67:503-514.

Hogan, J. S., R. N. González, R. J. Harmon, S. C. Nickerson, S. P. Oliver, J. W. Pankey, and K. L. Smith. 1999. Laboratory Handbook on Bovine Mastitis. Rev. ed. Natl. Mastitis Counc., Madison, WI.

Hovinen, M., A.-M. Aisla, and S. Pyörälä. 2006. Accuracy and reliability of mastitis detection with electrical conductivity and milk colour measurement in automatic milking. Acta Agric. Scand. A Anim. Sci. 56:121-127.

Hurnik, J. F., S. DeBoer, and A. B. Webster. 1984. Detection of health disorders in dairy cattle utilizing a thermal infrared scanning technique. Can. J. Anim. Sci. 64:1071-1073.

International Dairy Federation. 1999. Suggested interpretation of mastitis terminology. Pages 3-26 in IDF Bulletin 338. Brussels, Belgium.

Jones, B. F., and P. Plassmann. 2002. Digital infrared thermal imaging of human skin. IEEE Eng. Med. Biol. 21:41-48.
Lehtolainen, T., S. Suominen, T. Kutila, and S. Pyörälä. 2003. Effect of intramammary Escherichia coli endotoxin in early- vs. latelactating dairy cows. J. Dairy Sci. 86:2327-2333.

Loughmiller, J. A., M. F. Spire, S. S. Dritz, B. W. Fenwick, M. H Hosni, and S. B. Hogge. 2001. Relationship between mean body surface temperature measured by use of infrared thermography and ambient temperature in clinically normal pigs and pigs inoculated with Actinobacillus pleuropneumoniae. Am. J. Vet. Res. 62:676-681.

Mattila, T. 1985. Pages 18-19 in Diagnostic problems in bovine mastitis with special reference to new applications of milk antitrypsin. NAGase and bacterial growth. Thesis. University of Helsinki, Helsinki, Finland.

McGavin, D., and J. F. Zachary. 2007. Pathologic Basis of Veterinary Disease. 4th ed. Mosby Elsevier, St. Louis, MO.

Mottram, T., A. Rudnitskaya, A. Legin, J. L. Fitzpatrick, and P. D. Eckersall. 2007. Evaluation of a novel chemical sensor system to detect clinical mastitis in bovine milk. Biosens. Bioelectron. 22:2689-2693.

Nikkhah, A., J. C. Plaizier, M. S. Einarson, R. J. Berry, S. L. Scott, and A. D. Kennedy. 2005. Infrared thermography and visual examination of hooves of dairy cows in two stages of lactation. J. Dairy Sci. 88:2749-2753.

Paulrud, C. O., S. Clausen, P. E. Andersen, and M. D. Rasmussen. 2005. Infrared thermography and ultrasonography to indirectly monitor the influence of liner type and overmilking on teat tissue recovery. Acta Vet. Scand. 46:137-147.

Radostits, O. M., C. C. Gay, K. W. Hinchcliff, and P. D. Constable. 2007. Clinical findings of bovine mastitis. Page 563-574 in Veterinary Medicine: A Textbook of the Diseases of Cattle, Sheep, Pigs, Goats and Horses. 8th ed. Saunders Ltd., Philadelphia, PA.

Rasmussen, M. D. 2004. Detection and separation of abnormal milk in automatic milking systems. Pages $189-197$ in Automatic Milking-A Better Understanding. A. Meijering, H. Hogeveen, and C. J. A. M. de Koning, ed. Wageningen Academic Publishers, Wageningen, the Netherlands.

Schaefer, A. L., N. Cook, S. V. Tessaro, D. Deregt, G. Desroches, P. L. Dubeski, A. K. W. Tong, and D. L. Godson. 2004. Early detection and prediction of infection using infrared thermography. Can. J. Anim. Sci. 84:73-80.

Schaefer, A. L., N. J. Cook, J. S. Church, J. Basarab, B. Perry, C. Miller, and A. K. W. Tong. 2007. The use of infrared thermography as an early indicator of bovine respiratory complex in calves. Res. Vet. Sci. 83:376-384.

Scott, S. L., A. L. Schaefer, A. K. W. Tong, and P. Lacasse. 2000. Use of infrared thermography for early detection of mastitis in dairy cows. Can. J. Anim. Sci. 80:764-765. 